\title{
Consumers' perceptions of organic foods in Bangladesh: Challenges and opportunities
}

Md. Mizanur Rahman

\begin{abstract}
This study aims at exploring the consumers' perceptions of organic foods. Additionally, this paper attempts to explore the existing problems to promote organic production. The significant issues include lack of awareness about organic technology and consumers' trust in products and marketing systems. It is revealed that multi-factors influenced the choices of purchasing organic food. Educational qualification had a positive relationship with health and environmental awareness. However, there is a great potential to produce organic foods, particularly in a hilly region, and collect wild honey as organic foods from Sundarbans in Bangladesh. The cheaper wage is an opportunity for Bangladesh to intensify organic food production, generating decent jobs concomitantly. Lack of awareness, ecological consciousness, consumers' trust, certification, quality control mechanism, modern technologies, information literacy, storage capacity, and crop insurance were identified as the hindrances of flourishing the organic markets. In addition, the agricultural market chain is fragile, which is full of several intermediary groups. Furthermore, the availability of cheaper labor forces is a significant advantage of producing organic products that need intensive care.
\end{abstract}

Keywords: Organic Products; market chain; awareness level; education; intermediaries; public policy

\section{Introduction}

The organic food product is derived from Organic Agriculture (OA), which is becoming popular throughout the world day by day. In general, OA includes the growing of crops by a set of guidelines that prohibit synthetic products or chemicals such as fertilizers, pesticides, and plant growth promoters like hormones. This concept evolved in the first half of the $20^{\text {th }}$ century to respond to incremental chemical practices. The Codex Committee of the Food and Agriculture Organization of the United Nations defined, "Organic agriculture is a holistic production management system which promotes and enhances agroecosystem health, including biodiversity, biological cycles, and soil biological activity. This is accomplished by using, where possible, agronomic, biological, and mechanical methods, as opposed to using synthetic materials, to fulfill any specific function within the system" (FAO, 1999). Organic farming facilitates the usage of eco-friendly technologies and materials that enhances well-balanced agroecosystems. The other primary principle is the prohibition of artificial chemical use to ensure safe food production. It is noteworthy to mention that organic farming's primary goal is to balance soil health and productivity (FAO, 1999). 
At present, this system seems to be an ideal and valid solution to produce safe food and pure foods that minimize the negative consequences to human health and the environment resulted from chemical agriculture. Consumers are currently becoming conscious and critical about the quality of food products and by-products for a healthy life (Mottalib et al., 2018). OA has the potential to produce safe food in addition to environmental sustainability and preserving cultural heritage. Consequently, the demand for organic products has been growing significantly throughout the world, especially in developed countries, which indirectly control developing countries' export markets. Different studies in Africa, Asia, and Latin America indicate that organic farmers generally earn higher incomes than their conventional counterparts (UN, 2008). By realizing this fact, agricultural development in many countries has shifted from conventional agriculture to organic farming systems and introduced the organic agriculture policy.

Though Bangladesh is an agro-based country, most farmers are poor and equipped with traditional agricultural practices and systems. Conventional agricultural practices could not keep pace with the ongoing demands of the burgeoning population. Consequently, the government introduced the chemical-intensive farming system to meet increased needs. However, chemical agriculture contributed to achieving self-sufficiency in grain food production but created many negative consequences to human health and the environment. Agrochemicals have been linked to a wide range of human health hazards (Rahman et al., 2015), ranging from short-term impacts such as headaches and nausea to chronic effects like cancer, reproductive harm, and endocrine disruption. More than 03 million people are affected by pesticides, and about 370,000 deaths occur per year (WHO 2018). In Bangladesh, every year, a noticeable number of people are affected by agrochemicals and suffering from diseases (Shammi et al., 2020). Furthermore, depletion of soil organic matter is another concern of chemical agriculture (Biswas \& Naher, 2019). As a result, overall crop productivity has been declining in Bangladesh. Even a lack of organic foods is considered one of the significant challenges for developing inbound tourism in Bangladesh (Rahman, 2021).

In addition, the food safety issue is one of the major concerns for expanding international trade in agro-products. Buyers in the mainstream markets are increasingly enforcing stringent conditions on the suppliers to comply with various standards. OA has become an alternative tool to have safe food, sustain crop productivity, and increase soil fertility under such situations. However, many growers have come forward to produce organic products and are being sold in different super shops, especially in Dhaka city at a higher price. Consumers are interested in buying such organic products.

In most cases, they are confused about whether the products are organic due to a lack of certification. Although the Bangladesh government adopted organic agriculture policy - 2106', its implementation has not yet formally started. People's perceptions of organic foods have rarely been studied (Rahman \& Noor, 2016). The study aimed to assess the awareness level of consumers 
about organic products in Bangladesh. The study also strived to determine the current status of organic farming and explore the problems related to the extension of organic farming in Bangladesh.

\section{The emergence of organic food products in recent decades}

In the early 1990s, organic farming was started in Bangladesh on a minor scale. In Bangladesh, few Non-government Organizations (NGOs) started organic farming at first. These NGOs organize interested farmers, provide training, technical advice, financial support, and help market organic products. The organic farmers form groups and co-operate with each other towards a sustainable farming system. Currently, 75 NGOs and some conscious farmers are working towards organic farming (Sharma, 2006). Among the NGOs, 47 are directly involved in the production, where few numbers in awareness building (Sarker \& Itohara 2008). Among the NGO's Proshika, Unnayan Bikalper Nitinirdharoni Gobeshona (UBINIG), Bangladesh Resource Center for Indigenous Knowledge (BARCIK), and Research Initiatives, Bangladesh (RIB) ranked in the topmost position. Simultaneously, some private entrepreneurs like Kazi and Kazi Ltd, Shams Enterprise, Shabajpur Tea Estate Ltd are in the top place to invest in organic farming. Some entrepreneurs have already started to export their organic products in different developed countries. Today, horticultural crops, cotton, aromatic rice, and organic shrimp farming are being practiced on a small scale in Bangladesh to mainly export and target higher-income urban people. Currently, organic products are being sold through different super shops such as Agora, Meenabazar, Nandan, etc., they do not ensure fair prices for the producing farmers. Bangladesh Agricultural Research Institute (BARI) also took the initiative to conduct the necessary research regarding organic farming and established an Organic Block in her Experimental field at Joydebpur, Gazipur. Considering the global organic market trend and the expansion of OA by a private organization and NGO's in our country, the Bangladesh government adopted 'National Organic Agricultural Policy - 2016,' but the action plan has not yet started.

\section{Methodology}

The study examined the present status, prospects, and problems to disseminate organic technology. Secondary data, including books, journals, newspapers, and google searches of respective web addresses, were used. On the other hand, empirical data was collected using a structured questionnaire. A total of 100 respondents were interviewed from Meena Bazar, Agora, Shopno, Shossay Probortona, and Nandan super shop of Dhaka city. The questionnaire included demographic profiles, perception about organic foods, and costbenefit analysis. The collected data were processed and analyzed using simple statistics. The respondents were categorized based on age, educational qualification, annual income, occupation, health consciousness, and environmental awareness. Based on health consciousness, the respondents were classified as low (0-3), medium (4-6), and high (7-8) using the rating scale 
0-8. Similarly, based on environmental awareness, the respondents were classified as low (0-2), medium (3-4), and high (5-6) using the rating scale 0-6. Ten key informants, including academicians, researchers, NGO persons, government officials, farmers' leaders, and organic food entrepreneurs, were interviewed to know their opinions about this sector's opportunities and challenges. Content analysis was done based on the collected data (Krippendorf, 2004). Beforehand, the variables were categorized and coded accordingly.

\section{Results}

\section{Demographic profiles}

It is essential to know the consumers' demographic profiles, knowledge, and awareness level about organic foods to assess the domestic organic food market's potential. It is also essential to examine their attitudes and perceptions about the product and, ultimately, purchase decisions. The result indicates that the maximum number $(42 \%)$ of consumers fell into the middle age class, followed by a young age (39\%). About two-thirds of the consumers were male. The majority of the interviewees obtained a bachelor's degree, followed by a master's (Table 1). The study reveals that the higher educated male population from the middle-aged class tended to purchase organic foods.

Table-1: Demographic variables

\begin{tabular}{lll}
\hline Characteristics of the consumers & Distribution & $\%$ \\
Age (years) & Young $(18-40)$ & 39 \\
& Middle-aged (41 - 55) & 42 \\
& Old (> 55) & 19 \\
Gender & Male & 64 \\
Educational Background & Female & 36 \\
& < PSC & 11 \\
& PSC to HSC & 19 \\
& Degree & 39 \\
Occupation & >Degree & 31 \\
& Service & 19 \\
& Business & 33 \\
& Students & 25 \\
& Others & 22 \\
\hline
\end{tabular}

The rich people were more significant in number (39\%) whose monthly income was above fifty thousand takas. The trend declined with the decrease of the annual income. The lowest $(6 \%)$ number of consumers was under the poor class category, whose monthly income was not above fifteen thousand takas (Figure-1). The tendency of buying organic food depends on the income level. 


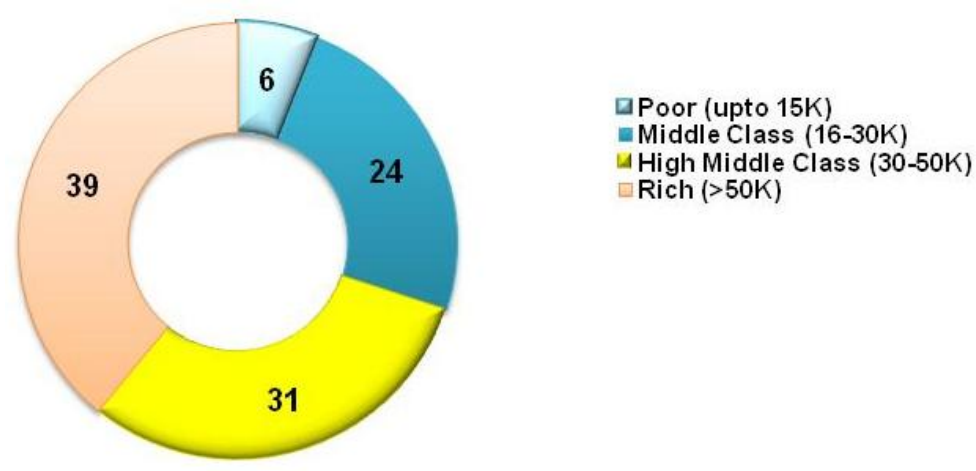

Figure-1: Distribution of the respondents according to their financial conditions

\section{Health consciousness}

The majority $(42 \%)$ of the consumers were driven by higher personal health issues, followed by medium consciousness. The least number $(22 \%)$ of consumers had low health consciousness (Figure-2). It can be argued that health consciousness works as a catalyst in consuming organic food products.

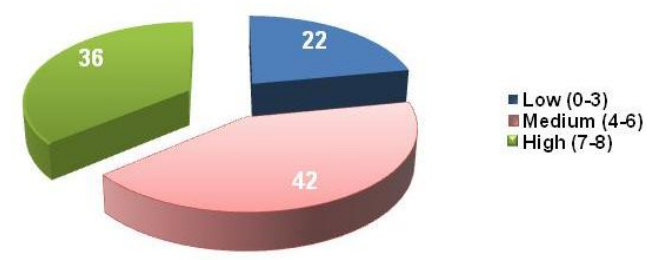

Figure-2: Distribution of the respondents according to their health consciousness

\section{Environmental awareness}

Half of the consumers were moderately conscious regarding environmental hazards that originate from chemical agriculture. About one-third of the consumers $(28 \%)$ had a high level of consciousness about ecological degradation. Ironically, $22 \%$ of the respondents exhibited low consciousness about the environmental (Figure-3). Therefore, health issue prevails over environmental problem contradictorily.

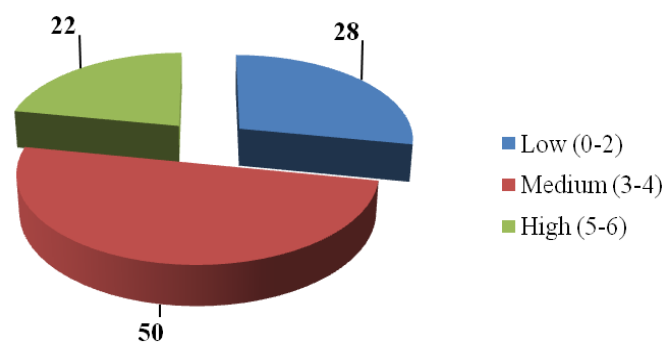

Figure-3: Distribution of the respondents according to their environmental awareness level 


\section{Perceptions about the meaning of organic food}

Despite having some knowledge and awareness about organic products, consumers are not consistent in interpreting the concept of 'organic.' Hence, they were requested to define organic food. The maximum number of consumers $(42 \%)$ perceived organic food as 'Foods without chemicals.' A significant portion (17\%) defined it as the 'Natural food' without further clarification. Interestingly, more than one-tenth of consumers had no idea about the meaning of organic food. Similarly, $6 \%$ of the consumers pointed out that organic food was something more though they could not explain (Table-2).

Table-2: Consumer's perceptions about the meaning of organic food

\begin{tabular}{lc}
\hline \multicolumn{1}{c}{ Comments } & Frequency (\%) \\
Not sure/no idea & 11 \\
Natural food & 17 \\
Foods without chemical fertilizers & 42 \\
Foods without pesticides & 8 \\
Traditional or Indigenous foods & 6 \\
Foods have grown with manure & 3 \\
Healthy Nutritious food & 8 \\
Something more & 5 \\
\hline
\end{tabular}

\section{Attitude toward organic food and practice}

Two-thirds of consumers (67\%) believed that organic agriculture could reduce the negative impacts of chemical agriculture, while one-third opposed this statement. About $89 \%$ of the consumers expressed their interest in acquiring knowledge about organic food production. In contrast, a minimal number $(11 \%)$ of the consumer did not show any interest. Total $72 \%$ of the respondents were ready to pay more money for the certification and quality control. A fragment of the consumers $(28 \%)$ had shown a negative attitude to spend the extra money associated with organic certification (Table-3).

Table-3: Consumers' attitude toward organic food and practice

\begin{tabular}{lcc}
\hline Statements & \multicolumn{2}{c}{ Response to comments } \\
& Yes (\%) & No (\%) \\
$\begin{array}{l}\text { Organic agriculture has the potential to minimize } \\
\text { the negative impacts of chemical agriculture }\end{array}$ & 67 & 33 \\
$\begin{array}{l}\text { Interested to know organic food culture and } \\
\text { practices }\end{array}$ & 89 & 11 \\
Willing to pay more money if needed for certification & 72 & 28 \\
\hline
\end{tabular}

\section{Relationships among different factors of consumers}

A decent relationship was observed between the educational level and financial solvency. The degree holders were more solvents who constituted the larger portion (Table-4). From illiterate to the Higher Secondary Certificates holders 
represented the 'poor' class. It is inspiring that despite poverty and lacking degree, this segment is the consumers of organic food.

Table-4: Cross-tabulation between financial condition and educational background of consumers

\begin{tabular}{lccccc}
\hline Educational background & \multicolumn{6}{c}{ The financial condition of consumer } & Sub-total \\
& Poor & Middle & High Middle & Rich & \\
$<$ PSC 1 & 3 & 6 & 3 & 0 & 12 \\
PSC- HSC ${ }^{2}$ & 3 & 5 & 5 & 6 & 19 \\
Degree & 0 & 6 & 11 & 22 & 39 \\
$>$ Degree & 0 & 7 & 12 & 11 & 30 \\
Total & 6 & 24 & 31 & 39 & 100 \\
\hline 1PSC = Primary school certificate; ${ }^{2} \mathrm{HSC}=$ Higher secondary certificate
\end{tabular}

It is revealed that the educated person is more conscious about their healths. Likewise, the health awareness level increased with the level of education (Table-5). Therefore, it can be argued that education is determinant in upscaling a healthy lifestyle.

Table-5: Cross-tabulation between educational background and personal health awareness of consumers

\begin{tabular}{lccccc}
\hline $\begin{array}{l}\text { Health } \\
\text { awareness }\end{array}$ & \multicolumn{5}{c}{$\begin{array}{c}\text { Educational background } \\
\text { PSC- }\end{array}$} \\
Low & 11 & HSC & Degree & >Degree & Sub-total \\
Medium & 0 & 8 & 3 & 0 & 22 \\
High & 1 & 3 & 17 & 17 & 42 \\
Total & 12 & 19 & 39 & 13 & 36 \\
\hline
\end{tabular}

Similarly, educated people were more conscious of environmental degradation and pollution. On the other hand, it was observed that the environmental consciousness was not as much a health issue (Table-6).

Table-6: Cross-tabulation between educational background and environmental awareness of consumers

\begin{tabular}{|c|c|c|c|c|c|}
\hline \multirow[t]{2}{*}{ Environmental awareness } & \multicolumn{4}{|c|}{ Educational background } & \multirow[t]{2}{*}{ Sub-total } \\
\hline & $<\mathrm{PSC}$ & PSC- HSC & Degree & $>$ Degree & \\
\hline Low & 8 & 6 & 6 & 8 & 28 \\
\hline Medium & 3 & 9 & 25 & 13 & 50 \\
\hline High & 1 & 4 & 8 & 9 & 22 \\
\hline Total & 12 & 19 & 39 & 30 & 100 \\
\hline
\end{tabular}

Most consumers were interested in paying more money for organic certification and quality control, which indicated a lack of trust in organic food products (Table-7). The willingness had a pragmatic relationship with the income level. 
The 'poor' class did not show any interest in paying more. In contrast, the 'rich' consumers did not care about spending more on purchasing healthy organic foods.

Table-7: Cross-tabulation between financial condition and willingness to pay more

\begin{tabular}{lccccc}
\hline $\begin{array}{l}\text { Willingness to pay more } \\
\text { money for organic food }\end{array}$ & \multicolumn{6}{c}{ The financial condition of consumers (\%) } & \multirow{2}{*}{ Sub- } \\
& Poor & Middle & High Middle & Rich & total \\
Yes & 0 & 14 & 23 & 36 & 73 \\
No & 6 & 10 & 8 & 3 & 27 \\
Total & 6 & 24 & 31 & 39 & 100 \\
\hline
\end{tabular}

\section{Opportunities}

The key informants opined that Bangladesh's hill tracts, comprising $10 \%$ of the total area, can quickly meet the buffer zone's requirement, particularly for producing organic fruits and vegetables (Figure 4). The principal criterion of organic farming is maintaining the buffer zone. Furthermore, indigenous knowledge of the local inhabitants (mostly tribal) is the additional advantages for introducing organic agriculture. They are rich in traditional knowledge and habituated not to use the chemicals for agricultural productions. Coupling the traditional experience with modern farming technologies and practices like biocontrol and integrated soil nutrient management can offer large-scale organic farming in the hilly areas.

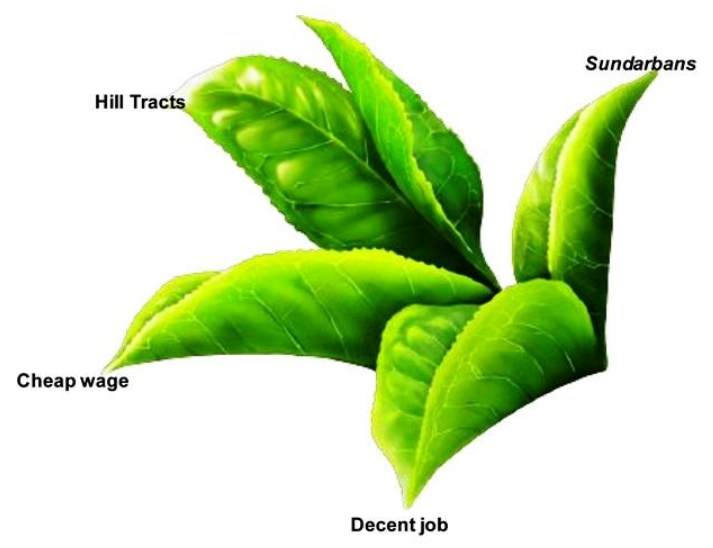

Figure 4: Key opportunities of organic agriculture in Bangladesh identified by the key informants

Furthermore, the Sundarban forest area is rich in pure, safe, and natural food like fishes, crabs, and honey. Wild honey, notably 'lotus honey,' is worldfamous considering its aroma, taste, nutrient composition, and sanctity (Rahman, 2020). Again, organic farming is a labor-intensive production method. Bangladesh is a densely populated country where laborers are available at cheaper wages. The availability of a labor force can be utilized for intensive care of highly valued organic products to achieve the product's global 
quality standard and earn more foreign currency. Thus, organic farming can generate employment and may open new trading opportunities for large farmers or entrepreneurs.

\section{Overreaching challenges}

The key informants opined that most people have lack awareness about the importance of organic food products. On the flip side, the producers are not acquainted with modern technology and agricultural practices. The populations have low ecological and environmental consciousness. The consumers are skeptical about the originality and authenticity of the products and rarely trust the advertisements. One of the crucial problems is that there is no effective quality control mechanism and a lack of trusted organic certification. It is highly challenging or near to impossible to distinguish organic products from conventional ones. Consequently, the consumers have to depend on producers' or sellers' statements entirely in favor of organic. The regulatory and institutional framework for the certification of organic products has not been developed yet. Other facilities like cold storage, vacuum packing units, processing unit, etc., are not well developed. There is not sufficient information on organic management strategies and market opportunities. The operational and institutional mechanism of risk insurance in organic farming is not well-defined. The agricultural market chain is fragile, where several intermediaries like Faria, Bepari, Aratdar, and wholesalers make the highest return. Resultantly, the producers are deprived of market services and earn less than expected. Simultaneously, consumers have to pay a high price.

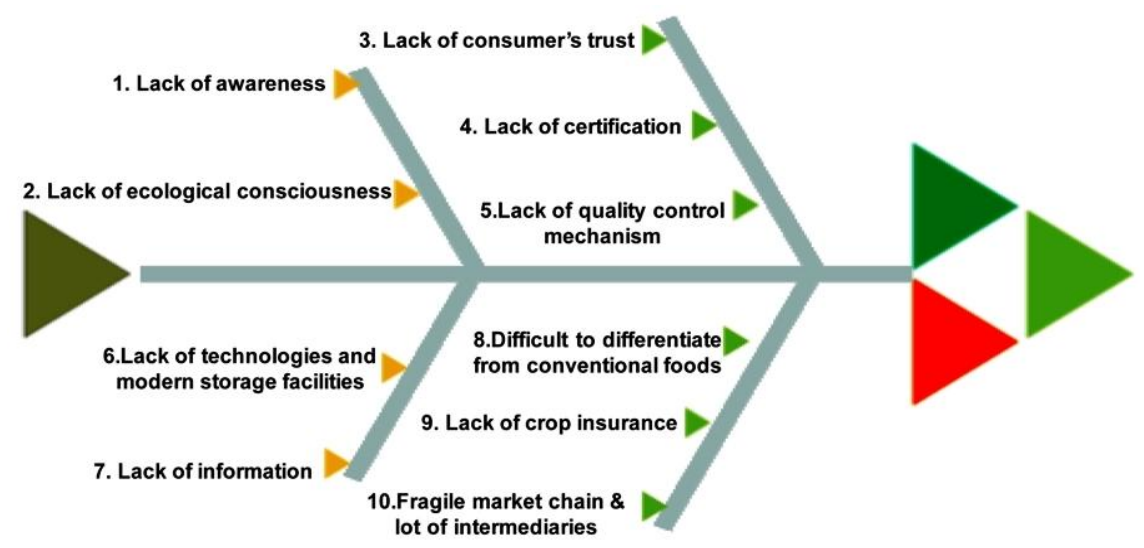

Figure 5: Key challenges of organic agriculture in Bangladesh identified by the key informants 


\section{Discussion}

Organic food is getting attention throughout the world due to rapidly increasing the consciousness of consumers. This study showed that the demographic and socioeconomic factors influenced interest and willingness to pay more for organic products. The result was supported by other studies (Meludu et al., 2011; Sanjay et al., 2011; Javanmardi et al., 2011). Educational level is a pivotal factor in determining the awareness level about health and the environment. Javanmardi et al. (2011) and Sharon \& Jonathon (2011) revealed that higher education increased both knowledge and awareness of health and the environment. Most of the consumers had a basic concept of the meaning of organic food. This implies the potential of the domestic organic food market in Bangladesh, although organic food has not been extensively available.

However, the willingness to pay more money for organic food increased with the income level or social status as it is involved with the extra money. Similarly, Cunningham (2002) reported a positive relationship between income and the willingness to purchase organic food. In contrast, few studies found no association between income and desire to pay for organic products (Wolf 2002). But in Bangladesh, annual income is a vital factor to buy organic food. Despite the higher cost, many consumers showed their interest in organic food and even paid a price premium to purchase such foods considering their health and environmental benefits. Sarker \& Ithora (2008) reported that most of the consumers $(90 \%)$ of Dhaka City want certified organic foods.

Many studies were carried out globally to examine the level of consumer awareness and knowledge about organic foods (Environics, 2001; Kenanoğlu \& Karahan, 2002; Cunningham, 2002). Ki \& Lee (2011) reported that nearly $90 \%$ of the organic food producers had little knowledge of organic agricultural products. They observed that many respondents preferred organic farming practices due to potential health benefits. Sharon \& Jonathon (2011) observed a positive feeling towards organic food products. He stated that a majority $(80 \%)$ of the respondents had the basic idea about organic food due to their higher educational background. They also reported that increasing healthconscious and environmental concerns had created a demand for organic food in recent years. Meludu et al. (2011) showed that most of the respondents were aware of the health benefits of organic agricultural products and environmental services in Nigeria. The majority of the respondents had a favorable attitude toward organic agricultural products. Similarly, maximum respondents were willing to pay more premiums to purchase organic agricultural products. Trust is the most critical factor that affects the buying intention (Sumi \& Kabir 2018; Hossain et al., 2007; Iqbal, 2015, Ashraf et al., 2019; Sekhon et al., 2014; Paul \& Rana 2012; Basha et al., 2015; Nasser et al., 2014; Mukul et al., 2013).

Sanjay et al. (2011) conducted a study on consumer behavior about India's organic products market. They revealed that the customers were motivated to 
purchase organic products due to their taste, quality, and environmentally friendly. The willingness to pay the premium price for organic products was attributed to its quality consideration. Jung (2011) found food safety as the biggest reason for purchasing organic food. The majority of the consumers $(78.9 \%)$ were satisfied with organic food. It was also reported that maximum respondents $(62.5 \%)$ intended to buy more organic food in the future. Javanmardi et al. (2011) showed that with an increased level of education, the rate of intention to consume organic products was raised in Iran. It further stated that $77 \%$ of respondents preferred to purchase organic products over non-organics, and the majority of respondents would pay a $25 \%$ or more price premium for organic products.

Sema (2011) identified the various constraints for expanding organic farming in India and reported that the lack of awareness of technology for organic production, high cost of certification, weak extension services, and weak market linkage was the critical limiting factors for organic production in India. The conversion period involved with organic agriculture was difficult due to temporarily declining yields and a lack of information and experiences (Lukas \& Cahn 2008). This is likely to be a significant constraint for poor farmers from adopting organic farming. Socioeconomic analysis has brought out by Grover \& Singh (2011) and stated that the organic growers were comparatively younger in an age that supported young farmers' tendency to adopt the new farming system. The literacy was marginally higher among organic growers. Organic farming was adopted by those farmers whose primary income source was agriculture. The overall operational size of organic and inorganic growers was not significantly different in the study area. Alam (2011) reported about three-fourths $(73 \%)$ of organic farmers grew vegetables, and the majority $(37 \%)$ of them sold their products to their respective providers. It was also reported that lack of capital and technical back up, insufficient organic inputs, marketing problems, and social and cultural barriers were the significant challenges of organic farming.

\section{Policy interventions}

In most countries, organic farming has been taken by either NGOs or by private organizations. Lately, government interventions have become obvious to formulate as well as to execute the National Organic Programme. Bangladesh is not the exception, and now it is time to promote organic farming by implementing the National Organic Agriculture Policy - 2016. The policy's success depends on how fast the policy is implemented. Developing Organic Standard and setting up the criteria for substances to be used or used in organic production in compliance with the International Federation of Organic Agriculture Movements (IFOAM) or any other well-established standards has become inevitable to boost organic culture.

The establishment of an Association of Organic Farmers and Entrepreneurs at the National and Regional level will allow them to be organized. Rahman and Akter (2020) reported that the pilot project, Village-based organization (VSO), 
helped the farmers unite and restore their inherent natural resources rights. The skills of the producers and processors can be improved by providing training and information sharing. Rahman et al. (2020a) found that the training improved knowledge, skills, and attitude towards sustainability. In this regard, educational institutions can take over the responsibility to update the syllabus relating to OA. Dissemination of information is highly warranted to develop organic markets. Incentives should be provided among the farmers for producing good quality organic manure, bio-pesticides, biofertilizers, etc. More action research should be carried out to formulate organic farming practices in the context of Bangladesh. Based on the dissemination of those findings, the farmers can bridge their knowledge gap.

Organic Agriculture should be considered the 'topmost priority sector' (under the export promotion policy), realizing the continued demand for organic products globally. Khas land should be leased among the proactive entrepreneurs and progressive farmers to establish "Export Agro-village" in each district. Contract farming will be important in the case of producing organic food products. Participating in national and international organic fair/trade shows, searching for the market, and strengthening the bondage is highly necessitated.

The agricultural market chain is distorted and fragile. A group of intermediaries determine the fate of the producers and consumers (Alam et al. 2020; Rahman et al. 2020b; Rahman and Neena 2018). The Department of Agriculture Extension should work closely with the Trading Corporation of Bangladesh (TCB) to uproot the intermediaries from the market and clear all market barriers. The target $2 \mathrm{c}$ of SDGs stresses adopting measures to ensure the proper functioning of food markets.

\section{Conclusions}

Consumer demand and organic trade-in products are rapidly increasing and becoming a reality throughout the world. Considering OA's trend, many developing countries have shifted from chemical to organic farming and accordingly formulated a national organic program. On the contrary, Bangladesh's organic farming progress is still at the primary stage compared with other developing countries and even Least Developed Countries. However, there is an excellent potential for organic farming, and Bangladesh could exploit the prospective global organic markets' opportunities. Certification is a prerequisite to popularize OA. Organic product legislation, standardization, and infrastructure in such development are also significant issues of policy concerns. It is quite difficult for poor Bangladeshi farmers to address these issues on their own. The success of organic markets depends entirely on how fast the organic agriculture policy is implemented. 


\section{References}

Alam, MK 2011, 'Status of Organic Farming in the Smallholder Group of Bangladesh', Proceedings of the Conference of the 17th IFOAM OWC-Organic is Life, 28 September - 01 October, Namyangju, Republic of Korea, vol. 1, pp. 8791.

Alam, S., Rahman, M.M. and Arif, A.A. (2020) "Challenges and opportunities in artisanal fisheries (Sonadia Island, Bangladesh): The role of legislative, policy and institutional frameworks". Ocean \& Coastal Management, https://doi.org/10.1016/i.ocecoaman.2020.105424.

Ashraf, M.A., Joarder, M.H.R. and Ratan, SRA (2019), "Consumers' anticonsumption behavior toward organic food purchase: an analysis using SEM", British Food Journal, Vol. 121 No. 1, pp. 104122. https://doi.org/10.1108/BFJ-02-2018-0072

Basha, M.B., Masson, C., Shamsudin, M.F., Hussain, H.I. and Salem, A.S. (2015), "Consumers attitude towards organic food", Procedia Economics and Finance, Vol. 31, pp. 444-452.

Biswas, J.C. \& Naher, U.A. (2019) Soil Nutrient Stress and Rice Production in Bangladesh, In: Mirza Hasanuzzaman, Masayuki Fujita, Kamrun Nahar, Jiban Krishna Biswas, Advances in Rice Research for Abiotic Stress Tolerance, Woodhead Publishing, https://doi.org/10.1016/B978-0-12-814332-2.00021$\underline{6}$.

Cunningham, R 2002, 'Canadian and Organic Retail Markets', Economics and Competitiveness Information, Alberta Agriculture, Food and Rural Development.

Environics International Ltd. 2001, 'Food Issues Monitor Survey 2001'.

FAO (1999) Committee on Agriculture, Organic Agriculture, Fifteenth Session, the Food and Agriculture Organization of the United Nations, Rome

Grover, DK \& Singh, I 2011, 'Socio-Economic Analysis of Organic Farming in Indian Punjab', Proceedings of the Conference of the 17th IFOAM OWC-Organic is Life, 28 September - 01 October, Namyangju, Republic of Korea, Vol 1:236240 .

Hossain, S.T.; Sugimoto, H.; Ueno, H.; Haque, S.M.R. (2007) Adoption of organic rice for sustainable development in Bangladesh. J. Org. Syst., 2: 2737.

Iqbal, M. (2015) Consumer Behavior of Organic Food: A Developing Country Perspective. Int. J. Mark. Bus. Commun., 4: 58-67. 
Javanmardi, J, Moment, H \& Zoroofi, M 2011, 'Public Preferences and Attitudes toward Organic Vegetables, a Survey from Seven Provinces of Iran', Proceedings of the Conference of the 17th IFOAM OWC-Organic is Life, 28 September - 01 October, Namyangju, Republic of Korea, 2:151.

Jeyaratnam, J 1985, 'Health problems of pesticide usage in the third world', British Journal of Industrial Medicine, vol. 42, no. 8, pp. 505-506.

Jung, MC 2011, 'Current Status of Korea'S Processed Organic Food Industry and Analysis an Consumers', Awareness. Proceedings of the Conference of the 17th IFOAM OWC - Organic is Life, 28 September - 01 October, Namyangju, Republic of Korea.

Kenanoğlu, Z \& Karahan, O 2002, 'Policy implementations for organic agriculture in Turkey'. British Food Journal, vol. 104, pp. 300-318.

Ki, JD \& Lee, HW 2011, 'Study on Current Status and Consumption Trends of the Korean Organic Farming', Proceedings of the Conference of the $17^{\text {th }}$ IFOAM OWC - Organic is Life, 28 September - 01 October, Namyangju, Republic of Korea.

Krippendorf, K. (2004). Content Analysis: An Introduction to its Methodology. Beverly Hills, CA: Sage Publications.

Lukas, M \& Cahn, M 2008 'Organic agriculture and rural livelihood in Karnataka, India', Book of Abstracts, 16 the IFOAM Organic World Congress, Modena, Italy 16-20 June, P. 193.

Meludu, NT, Adeoluwa, AA \& Abolade, TJ 2011, 'Consumer's Attitudes and Willingness to Pay for Organic Agricultural Products and the Socio-Economics of Niche Market Creation: a Social Ecology Paradigm for the Adoption of Organic Cultivation in Nigeria', Proceedings of the Conference of the 17th IFOAM OWC - Organic is Life, 28 September - 01 October, Namyangju, Republic of Korea.

Mottalib, K.A., Ragut, D.B., Kruseman, G. and Erenstein, D. (2018), "Evolving food consumption patterns of rural and urban households in developing countries: a Bangladesh case", British Food Journal, Vol. 120 No. 2, pp. 392 408.

Mukul, A., Afrin, S. and Hassan, M. (2013), "Factors affecting consumers' perceptions about organic food and their prevalence in Bangladeshi organic preference", Journal of Business, Vol. 1 No. 5, pp. 112-118.

Nasser, M., Yusoff, R., Islam, R. and Nasser, A. (2014), "Effects of consumer's trust and attitude toward online shopping", American Journal of Economics and Business Administration, Vol. 6 No. 2, pp. 58-71. 
Paul, J. and Rana, J. (2012), "Consumer behavior and purchase intention for organic food”, Journal of Consumer Marketing, Vol. 29 No. 6, pp. 412-422.

Rahman MM \& Akter M (2020) Effectiveness of Village-Based Organization (VBO) in improving the livelihood of the rural community in Bangladesh, Bangladesh Journal of Public Administration, 28(2): 27-37.

Rahman MM (2020) Impact of increased salinity on the plant community of the Sundarbans Mangrove of Bangladesh, Community Ecology, 21 (3): 273-284, DOI: $10.1007 / \mathrm{s} 42974-020-00028-1$.

Rahman MM (2021) Inbound tourism in Bangladesh: Trend of competitiveness, Bangladesh Journal of Public Administration, 29(2) (forthcoming)

Rahman, K.M. and Noor, N.A.M. (2016), "Evaluating gaps in consumer behavior research on organic foods: a critical literature review under Bangladesh context", Journal of Marketing and Consumer Behavior in Emerging Markets, Vol. 1 No. 3, pp. 42-50.

Rahman, M.A., Sultan, M.Z., Rahman, M.S. and Rashid, M.A. (2015), "Food adulteration: a serious public health concern in Bangladesh", Bangladesh Pharmaceutical Journal, Vol. 18 No. 1, pp. 1-7.

Rahman, M.M. and Neena, SB (2018), "The marketing system of agricultural products in Bangladesh: a case study from Sylhet district", Bangladesh Journal of Public Administration (BJPA), Vol 26 No 2, pp. 61-78.

Rahman, M.M., Ahmed, M.M., Ali, M.Y. and Adnan, S. et al. (2020a), "How does the Foundation Training Course Enhance the Capacity of The Young Civil Servants to Achieve Sustainable Development Goals (SDGs)? A Study on Bangladesh Public Administration Training Centre", in Alam, M.A., Alam, F. and Begum, D. (Eds.), Knowledge Management, Governance and Sustainable Development: Lessons and Insights from Developing Countries. India: Routledge, http://doi.org/10.5281/zenodo.4390495.

Rahman, M.M., Alam, M.A., Rahman, M.M., Mamun, M. and Alam, A. (2020b), "Challenges of Artisanal Fishermen: A Case Study from Sonadia Island, Bangladesh", in Alam, M.A., Alam, F. and Begum, D. (Eds.), Knowledge Management, Governance and Sustainable Development: Lessons and Insights from Developing Countries. India: Routledge, http://doi.org/10.5281/zenodo.4405054.

Sanjay, K, Mahesh, C \& Subrahamanyeswari, B 2011, 'Study of Consumer Behavior of Organic Products Marketed through Government Sponsored Marketing Centers in Uttarakhand State of India', Proceedings of the Conference of the 17th IFOAM OWC - Organic is Life, 28 September - 01 October, Namyangju, Republic of Korea. 
Sarker, MA \& Itohara, Y 2008, 'Organic farming and poverty elimination: A suggested model for Bangladesh', Journal of Organic System, vol. 3, pp. 6879 .

Sekhon, H., Ennew, C., Kharouf, H. and Delvin, J. (2014), "Trustworthiness and trust: influences and implications", Journal of Marketing Management, Vol. 30 Nos 3/4, pp. 409-430.

Sema, A 2011, 'North East INDIA - a Land of Organic Mountains', Proceedings of the Conference of the 17th IFOAM OWC - Organic is Life, 28 September - 01 October, Namyangju, Republic of Korea.

Shammi, M., Sultana, A., Hasan, N., Rahman, M.M., Islam,M.S., BodrudDoza, M. \& Uddin, M.K. (2020) Pesticide exposures towards health and environmental hazard in Bangladesh: A case study on farmers' perception, Journal of the Saudi Society of Agricultural Sciences, Vol. 19, No. 2,pp.161173, https://doi.org/10.1016/j.jssas.2018.08.005.

Sharma, AK 2006, 'Adoption and Success' in A Handbook of Organic Farming, Published by Agrobios (India), p. 434.

Sharon, CH \& Jonathan, JWW 2011, 'Consumer Behavior on Organic Products in Hong Kong', Proceedings of the Conference of the 17th IFOAM OWC-Organic is Life, 28 September - 01 October, Namyangju, Republic of Korea.

Sumi RS, Kabir G. (2018) Factors Affecting the Buying Intention of Organic Tea Consumers of Bangladesh. Journal of Open Innovation: Technology, Market, and Complexity, 4(3):24.

UN (2008) Best Practices for Organic Policy-what developing country Governments can do to promote the organic agriculture sector', United Nations Conference on Trade and Development United Nations Environment Programme, New York and Geneva.

WHO (2018) Chemical Safety - Activity Report 2018, https://apps.who.int/iris/

Wolf, MM 2002, 'An Analysis of the Impact of Price on Consumer Interest in Organic Grapes and a Profile of Organic Purchasers', Proceedings of the American Agricultural Economics Association Annual Meeting, Long Beach, California, July 28-31, 2002. 